\title{
Behavioral State Instability in Orexin Knock-Out Mice
}

\author{
Takatoshi Mochizuki, ${ }^{1}$ Amanda Crocker, ${ }^{1}$ Sarah McCormack, ${ }^{1}$ Masashi Yanagisawa, ${ }^{2}$ Takeshi Sakurai, ${ }^{3}$ and \\ Thomas E. Scammell ${ }^{1}$ \\ ${ }^{1}$ Department of Neurology, Beth Israel Deaconess Medical Center, Boston, Massachusetts 02115, ${ }^{2}$ Department of Molecular Genetics, University of Texas \\ Southwestern Medical Center at Dallas, Dallas, Texas 75390, and '3Department of Pharmacology, Institute of Basic Medical Sciences, University of Tsukuba, \\ Tsukuba, Ibaraki 305-8575, Japan
}

Narcolepsy is caused by a lack of orexin (hypocretin), but the physiologic process that underlies the sleepiness of narcolepsy is unknown. Using orexin knock-out (KO) mice as a model of narcolepsy, we critically tested the three leading hypotheses: poor circadian control of sleep and wakefulness, inadequate activation of arousal regions, or abnormal sleep homeostasis. Compared with wild-type (WT) littermates, orexin KO mice had essentially normal amounts of sleep and wake, but wake and non-rapid eye movement (NREM) bouts were very brief, with many more transitions between all behavioral states. In constant darkness, orexin KO mice had normal amplitude and timing of sleep-wake rhythms, providing no evidence for disordered circadian control. When placed in a new, clean cage, both groups of mice remained awake for $\sim 45 \mathrm{~min}$, demonstrating that, even in the absence of orexin, fundamental arousal regions can be engaged to produce sustained wakefulness. After depriving mice of sleep for $2-8 \mathrm{hr}$, orexin $\mathrm{KO}$ mice recovered their NREM and rapid eye movement sleep deficits at comparable rates and to the same extent as WT mice, with similar increases in EEG delta power, suggesting that their homeostatic control of sleep is normal. These experiments demonstrate that the fragmented wakefulness of orexin deficiency is not a consequence of abnormal sleep homeostasis, poor circadian control, or defective fundamental arousal systems. Instead, the fragmented behavior of orexin $\mathrm{KO}$ mice may be best described as behavioral state instability, with apparently low thresholds to transition between states.

Key words: orexin; hypocretin; narcolepsy; sleepiness; transitions; sleep

\section{Introduction}

Narcolepsy is characterized by chronic sleepiness in association with brief episodes of muscle weakness, known as cataplexy (for review, see Scammell, 2003). Approximately 90\% of people with this common sleep disorder lack the hypothalamic neuropeptide orexin (hypocretin) (Mignot et al., 2002), and orexin knock-out (KO) mice have a phenotype very similar to that of the human disorder (Chemelli et al., 1999; Willie et al., 2003). These findings show that a loss of orexin is sufficient to produce narcolepsy, but the physiologic process that underlies the sleepiness of narcolepsy is unknown.

Three neurobiologic models have been hypothesized to account for this sleepiness. The orexin neurons heavily innervate and excite wake-promoting brain regions, such as the aminergic and cholinergic neurons of the brainstem, hypothalamus, and basal forebrain (Peyron et al., 1998; Hagan et al., 1999; Eggermann et al., 2001; Eriksson et al., 2001). In addition, orexin promotes wakefulness when injected near the locus ceruleus (LC) (Bourgin et al., 2000), and histaminergic signaling appears necessary for the wake-promoting actions of orexin (Huang et al.,

Received Feb. 18, 2004; revised May 6, 2004; accepted May 20, 2004.

This study was supported by National Institutes of Health Grants MH62589 and HL02013. We thank C. B. Saper, J. M. Mullington, R. A. España, T. C. Chou, and J. T. Willie for their thoughtful comments on this manuscript.

Correspondence should be addressed to Thomas E. Scammell, Department of Neurology, Beth Israel Deaconess Medical Center, 77 Avenue Louis Pasteur, Boston, MA 02115. E-mail: tscammel@bidmc.harvard.edu. DOI:10.1523/JNEUROSCI.0586-04.2004

Copyright $\odot 2004$ Society for Neuroscience $\quad$ 0270-6474/04/246291-10\$15.00/0
2001; Yamanaka et al., 2002). Thus, the sleepiness of orexin deficiency may simply be a consequence of inadequate activation of these fundamental arousal regions.

Abnormal sleep homeostasis is also hypothesized to cause the excessive sleepiness of narcolepsy (Tafti et al., 1992b; Besset et al., 1994). Narcoleptics often feel sleepy after just a few hours of wakefulness, and, after $24 \mathrm{hr}$ of sleep deprivation, people with narcolepsy have shorter sleep latencies and more deep non-rapid eye movement (NREM) sleep than controls (Tafti et al., 1992a). Considered together, these observations suggest a heightened sensitivity to or a more rapid accumulation of sleep pressure in narcolepsy.

Other researchers have hypothesized that the sleepiness of narcolepsy is caused by impaired circadian control of sleep and wake (Kripke, 1976; Dantz et al., 1994; Broughton et al., 1998). Circadian rhythms are governed by the suprachiasmatic nucleus (SCN) and play an essential role in the timing of sleep and wakefulness (Klein et al., 1991; Dijk and Czeisler, 1995). The SCN may also help consolidate wakefulness because monkeys with lesions of the SCN have very short bouts of wake (Edgar et al., 1993), although this phenomenon is less apparent in SCN-lesioned rodents (Mistlberger et al., 1983). The orexin neurons are anatomically well positioned to time sleep-wake behavior because they receive direct and indirect projections from the SCN (Abrahamson et al., 2001; Lu et al., 2001; Chou et al., 2003), and they may relay this circadian information to arousal regions. People with narcolepsy have normal amounts of sleep over $24 \mathrm{hr}$ (Nobili et al., 
1995), but the broad distribution of sleep and the occurrence of rapid eye movement (REM) sleep at all times of day led to the idea that their sleepiness might be caused by a decrease in the amplitude of the circadian signals that time sleep and wakefulness (Broughton et al., 1998).

We critically tested these hypotheses by examining the sleepwake behavior of orexin $\mathrm{KO}$ mice under conditions that assess endogenous circadian rhythms, the integrity of fundamental arousal systems, and the homeostatic control of sleep.

\section{Materials and Methods Animals}

Founder orexin KO mice were on a C57BL/6J-129/SvEV background, and their offspring were backcrossed with C57BL/6J mice for six to eight generations. These experiments used seven male $\mathrm{KO}$ mice and eight wild-type (WT) male littermates, all 11 weeks old and weighing 26-28 gm. Mice were genotyped using PCR with a neo primer, 5' -CCGCTATCAGGACATAGCGTTGGC, or a genomic primer, 5' GACGACGGCCTCAGACTTCTTGGG, and a genomic primer, $3{ }^{\prime}$-TCACCCCCTTGGGATAGCCCTTCC, common to KO and WT mice. All experiments were approved by the Institutional Animal Care and Use Committees of Beth Israel Deaconess Medical Center and Harvard Medical School.

\section{Surgery and electroencephalogram-electromyogram recordings}

Mice were anesthetized with ketamine-xylazine (100 and $10 \mathrm{mg} / \mathrm{kg}$, i.p.) and implanted with electroencephalogram (EEG) and electromyogram (EMG) electrodes for polysomnogram recording. EEG signals were recorded using two ipsilateral stainless-steel screws $(1.5 \mathrm{~mm}$ to the right of the sagittal suture, $1 \mathrm{~mm}$ anterior to bregma, and $1 \mathrm{~mm}$ anterior to lambda). EMG signals were acquired by a pair of multistranded stainlesssteel wires inserted into the neck extensor muscles. These leads were attached to a $2 \times 2$ pin header that was secured to the skull using dental acrylic. A telemetric temperature transmitter (TA-F20; Data Sciences International, St. Paul, MN) was placed in the peritoneal cavity of all mice. Mice were housed individually for $9 \mathrm{~d}$ after surgery. They were then transferred to recording cages in a sound-attenuated chamber with a 12 hr light/dark (LD) cycle (30 lux; lights on at 7:00 A.M. and off at 7:00 P.M.) and a constant temperature $\left(22-24^{\circ} \mathrm{C}\right)$. They had ad libitum access to food and water and acclimated to the recording cables for another $5 \mathrm{~d}$.

The EEG-EMG signals were acquired using Grass Instruments (West Warwick, RI) model 12 amplifiers and digitized at $128 \mathrm{~Hz}$ using a sleep scoring system (Sleep Sign; Kissei Comtec, Matsumoto, Japan). The signals were digitally filtered (EEG, $0.3-30 \mathrm{~Hz}$; EMG, 2-100 Hz) and semiautomatically scored in $10 \mathrm{sec}$ epochs as wake, NREM, or REM sleep. This preliminary scoring was visually inspected and corrected when appropriate.

People with narcolepsy have cataplexy, defined as emotionally triggered episodes of muscle weakness with preserved consciousness, and orexin $\mathrm{KO}$ mice have similar events during active wake (previously referred to as "abrupt behavioral arrests") (Chemelli et al., 1999; Willie et al., 2003). Although EEG theta activity and atonia occur in both cataplexy and REM sleep (Guilleminault et al., 1974; Mitler and Dement, 1977; Dyken et al., 1994; Willie et al., 2003), cataplexy is a distinct state, based on behavioral and physiologic criteria. In narcoleptic dogs, neurons of the LC, dorsal raphe, and tuberomammillary nucleus (TMN) fall silent during REM sleep, but, during cataplexy, the raphe and the TMN fire at moderate and high rates, respectively (John et al., 2004; Wu et al., 2004). Cataplexy in orexin $\mathrm{KO}$ mice is immediately preceded by active wake with grooming, climbing, and ambulation and is immediately followed by an abrupt resumption of activity (Chemelli et al., 1999; Willie et al., 2003).

Using infrared video recordings of five uninstrumented KO mice, housed together in a regular cage, we observed 5.7 episodes of cataplexy per hour, lasting an average of $52 \pm 14 \mathrm{sec}$, during the first $2 \mathrm{hr}$ of the dark period (a time when cataplexy is common). Because Willie and colleagues have shown that $80 \%$ of cataplexy is accompanied by EEG theta (4-9 Hz) activity (Willie et al., 2003), we counted cataplexy episodes using EEG and EMG recordings alone, provided that the event (1) begins with an abrupt transition from active wake to atonia with EEG theta activity and (2) is terminated by an abrupt return from atonia and theta to active wake (supplemental Fig. 1, available at www.jneurosci.org/cgi/ content/full/24/28/6291/DC1). Using this operational definition with EEG-EMG recordings, orexin KO mice had 5.2 occurrences of cataplexy, lasting an average of $67 \pm 6 \mathrm{sec}$, during the first $2 \mathrm{hr}$ of the dark period. On rare occasions, orexin $\mathrm{KO}$ mice had brief episodes of atonia during sustained wake that lacked clear theta or delta $(0.5-4 \mathrm{~Hz})$ activity, and these indeterminate epochs were scored as a fifth state. These atypical episodes accounted for only $0.2 \%$ of the total recording time and were omitted from additional analysis. WT mice never had cataplexy or this fifth state.

\section{Analysis of sleep-wake bouts}

To examine the ability of mice to maintain behavioral states, we analyzed the distribution of behavioral states as a function of bout length (Trachsel et al., 1991; Franken et al., 1999). No minimal criteria were used, and a bout could be as short as one epoch. All bouts of each state were separated into eight bins of increasing duration $(<30,40-70,80-150,160-310$, $320-630,640-1270,1280-2550$, and $>2560 \mathrm{sec}$ ). The amount of state in each bin was time weighted and normalized by the total amount of the state in each animal during the observation period and then averaged in groups to produce a time-weighted frequency histogram.

NREM and REM sleep latencies were calculated as the time from an intervention (cage change or the end of sleep deprivation) to the first epoch of NREM or REM sleep. To measure the duration of sleep cycles, we used an approach similar to that used previously in rats (Trachsel et al., 1991). We defined the sleep cycle as beginning at the onset of NREM sleep and as ending at the offset of REM sleep, allowing for brief awakenings that were no longer than $20 \mathrm{sec}$. Cycles were considered incomplete and were excluded from analysis if they lacked REM sleep or at least $30 \mathrm{sec}$ of NREM before REM sleep. In both groups, the discarded NREM sleep amounted to $30-40 \%$ of total NREM sleep in the $12 \mathrm{hr}$ light period, but only $10 \%$ of REM sleep was excluded.

\section{EEG spectral analysis}

EEG spectral power was calculated in $0.25 \mathrm{~Hz}$ bins using fast Fourier transformation of each $10 \mathrm{sec}$ epoch. Power in the $0.5-25 \mathrm{~Hz}$ range of artifact-free epochs was averaged in groups across each behavioral state in the dark and light periods, and the mean values were plotted in $0.25 \mathrm{~Hz}$ bins. To measure the effects of sleep deprivation on EEG power, the total power in the delta range during NREM sleep or in the theta range during REM sleep was compared between the first $4 \mathrm{hr}$ after sleep deprivation ended and the corresponding $4 \mathrm{hr}$ interval on the baseline day. This interval was chosen to ensure adequate amounts of NREM and REM sleep for analysis.

\section{Experimental design}

To examine the ability of mice to maintain wakefulness, they were tested across a variety of conditions. Baseline recordings were on day 1 , cagechange task on day 3 , and sleep deprivation on days 6 ( $2 \mathrm{hr}), 9$ ( $4 \mathrm{hr}$ ), and $12(8 \mathrm{hr})$. On day 15 , we turned off the lights in the recording chambers and recorded free-running behavior on day 20. Sleep-wake behavior was analyzed in 10 sec epochs, and body temperature and locomotor activity were recorded every $5 \mathrm{~min}$.

Sleep-wake behavior under a $12 \mathrm{hr}$ LD cycle. To establish the baseline behavior of mice, EEG-EMG recordings were analyzed over $24 \mathrm{hr}$, beginning at the onset of the dark period (7:00 P.M.).

Behavior in constant darkness. Some researchers have hypothesized that the circadian promotion of wakefulness is impaired in narcolepsy (Kripke, 1976; Broughton and Mullington, 1994; Dantz et al., 1994; Broughton et al., 1998), so we housed mice in constant darkness (DD) for $5 \mathrm{~d}$ and then recorded behavior for $48 \mathrm{hr}$, beginning at 1:00 P.M. the next day. The free-running periods of individual animals were estimated using the body temperature rhythm during the $7 \mathrm{~d}$ of DD (Circadia; Behavioral Cybernetics, Cambridge, MA), and all data were aligned according to the circadian time of the animals. The amplitudes of sleep and wake rhythms were calculated using the circadian index ( mean $_{\text {subjective night }}-$

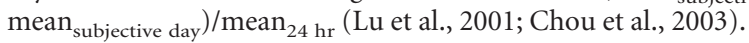


Sleep-wake behavior with behavioral challenge. We used a cage-change task to examine the ability of mice to maintain wakefulness in a novel environment (Parmentier et al., 2002; Hunsley and Palmiter, 2003). On the regular LD cycle, mice were transferred to identical cages with clean bedding at 1:00 P.M., and behavior was assessed over the next $4 \mathrm{hr}$.

Total sleep deprivation. To examine the integrity of sleep homeostasis, all mice were sleep deprived by gentle handling for 2, 4, or $8 \mathrm{hr}$ (Franken et al., 1999). The deprivation began at lights on, and behavior was recorded for the next $24 \mathrm{hr}$. To examine the kinetics of recovery sleep, we calculated the cumulative change in the amounts of NREM and REM sleep. Hourly amounts of NREM and REM sleep on the baseline day were subtracted from those on the sleep deprivation day, and the cumulative deficit was tallied over the recovery period. The NREM and REM sleep recovery rates were calculated for each animal using linear regression across the recovery period, and the rates were then averaged within groups.

\section{Statistical analysis}

All results are expressed as means \pm SEM. Hourly changes in behavior, EEG power spectra, and time-weighted bout distributions were compared between WT and KO mice using two-way, repeated measures ANOVA with a post hoc, two-tailed Student's $t$ test. Pairwise comparisons between WT and KO mice (e.g., sleep-wake amounts, numbers and duration of bouts, number and proportions of state transitions, sleep latencies, and rate and extent of recovery from sleep deprivation) were determined using unpaired, two-tailed Student's $t$ tests. Within-group responses to sleep deprivation (dose-dependent effects on the amount and latency of recovery sleep, as well as EEG delta and theta power during sleep) were analyzed using paired, two-tailed Student's $t$ tests.

\section{Results}

Baseline sleep-wake behavior on an LD cycle

The amounts of wake and sleep in orexin knock-out mice were nearly normal. Compared with WT littermates, orexin KO mice had the same hourly amounts of wake and NREM sleep, using a two-way ANOVA (Fig. 1A). Across time, orexin KO mice had slightly more REM sleep than WT mice (genotype $\times$ time, $F=$ $1.72 ; p=0.02)$, but this increase was much smaller than reported previously (Chemelli et al., 1999; Willie et al., 2003), most likely because we scored cataplexy as a separate state. When viewed as a percentage of total sleep time, orexin KO mice had slightly more REM sleep during the dark period ( 12.5 vs $10.3 \%$ in WT mice; $p=0.04)$. Nearly all episodes of cataplexy occurred during the dark period, particularly when the amount of REM sleep was $<4 \% / \mathrm{hr}$. During the $12 \mathrm{hr}$ dark and light periods, the mean amounts of sleep and wake were almost the same in WT and $\mathrm{KO}$ mice, except that, during the dark period, KO mice spent $3.8 \%$ of their time in cataplexy and had slightly less wake $(p<$ 0.05) (Fig. $1 B$ ).

Although the amounts of sleep and wake were almost normal in orexin $\mathrm{KO}$ mice, the durations of these behaviors were very short (Fig. 2A). During the dark period, wake bouts lasted an average of only $3.4 \mathrm{~min}$ in orexin $\mathrm{KO}$ mice compared with 8.2 min in WT mice. Wake bouts were also shorter during the light period, although the difference was less striking. The short wake bouts of orexin $\mathrm{KO}$ mice were not merely a result of disruption of wakefulness by cataplexy because transitions into cataplexy accounted for only $15 \%$ of all transitions out of wakefulness, during the dark period. Orexin KO mice also failed to produce long bouts of NREM sleep at all times, although REM bouts were only significantly shorter during the light period. The mean duration of cataplexy did not change over time. As expected, episodes of wake and sleep occurred much more frequently, with approximately twice as many wake and NREM bouts during the dark period and smaller increases during the light period (Fig. $2 B$ ).

This inability to maintain long bouts of wake may be one of
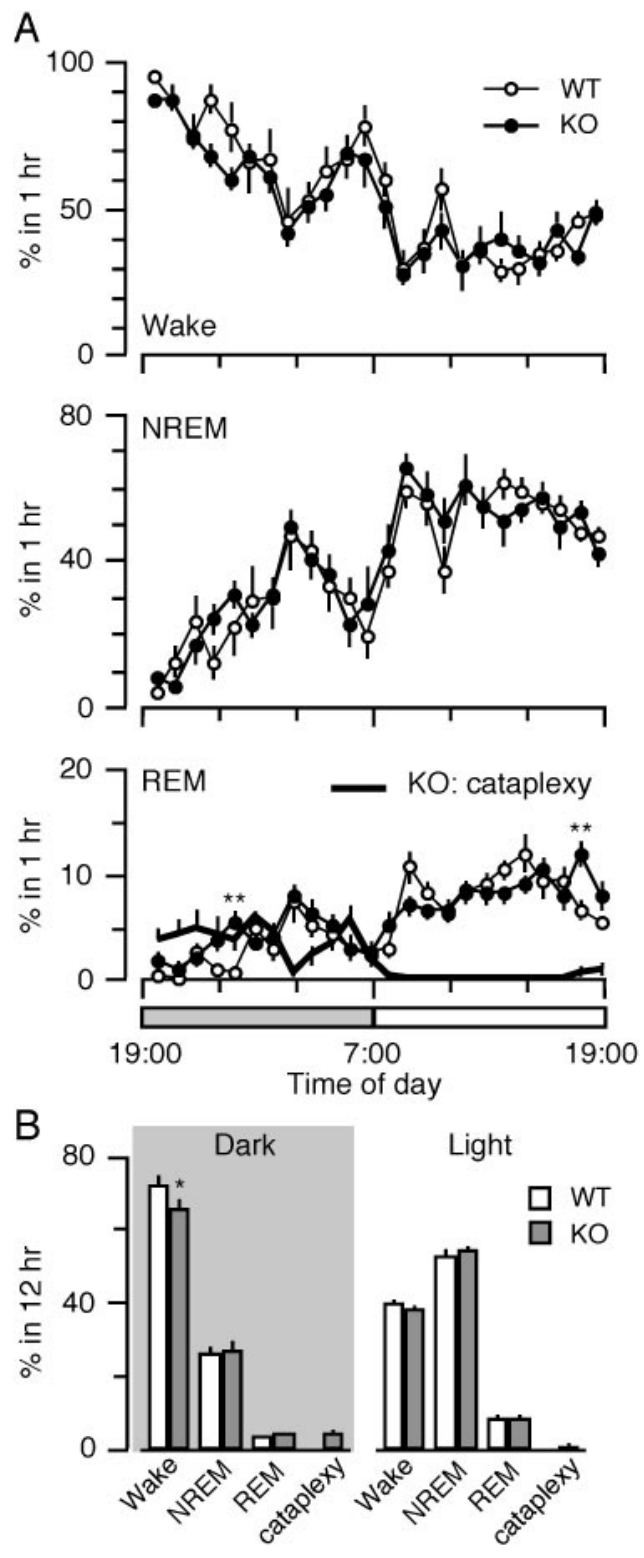

Figure 1. Orexin $\mathrm{KO}$ mice have nearly normal amounts of wake and sleep on a $12 \mathrm{hr} \mathrm{LD}$ cycle. $A$, Orexin $\mathrm{KO}$ mice have normal hourly amounts of wake and NREM sleep and slightly more REM sleep. Cataplexy occurs almost exclusively during the dark period, especially during times of relatively little REM sleep. $B$, Across the $12 \mathrm{hr}$ dark and light periods, WT and orexin KO mice have similar amounts of NREM and REM sleep. Orexin KO mice have slightly less wake during the dark period, perhaps because of cataplexy during this period. This and all other experiments used seven male orexin KO mice and eight WT male littermates. ${ }^{*} p<0.05$; ${ }^{* *} p<0.01$ compared with WT mice.

the most important elements of the narcolepsy phenotype because it could easily account for the daytime sleepiness of people with narcolepsy. To examine the maintenance of wakefulness in greater detail, we analyzed wake bouts during the dark period as a function of bout length (Fig. 2C). WT mice often had wake bouts lasting $>2560 \mathrm{sec}(42.7 \mathrm{~min})$, particularly during the first few hours of the dark period. Orexin $\mathrm{KO}$ mice rarely produced any of these very long bouts but instead had many short- to mid-length bouts. When viewed as a percentage of the total amount of wake during the dark period, $82 \%$ of wake occurred in bouts lasting over $1280 \mathrm{sec}$ (21.2 $\mathrm{min}$ ) in WT mice, but this accounted for only $13 \%$ of wake in orexin $\mathrm{KO}$ mice. Instead, $80 \%$ of their wake occurred in bouts lasting $80-1270 \mathrm{sec}(1.3-21.2 \mathrm{~min})$. 
The short sleep bouts of orexin $\mathrm{KO}$ mice were accompanied by short sleep cycles during the light period. A sleep cycle was defined as the time from the beginning of a NREM sleep episode to the end of the immediately subsequent REM sleep. The average sleep cycle in WT mice lasted $6.4 \pm 0.1 \mathrm{~min}$, with some cycles lasting up to $20 \mathrm{~min}$ (Fig. 2D). Orexin KO mice had $34 \%$ more sleep cycles during the $12 \mathrm{hr}$ light period, and an average cycle lasted $4.0 \pm 0.2 \min (p<0.01)$. When viewed as a percentage of all sleep cycles, orexin $\mathrm{KO}$ mice had many more cycles lasting $<3$ min and fewer cycles lasting $>9 \mathrm{~min}$ (genotype $\times$ duration, $F=12.89 ; p<0.01$ ).

These short bouts of sleep and wake in orexin $\mathrm{KO}$ mice were accompanied by many more transitions between all states (Fig. 3). However, the relative distribution of transitions between wake, NREM, and REM sleep was normal in orexin $\mathrm{KO}$ mice, demonstrating that, with the exception of cataplexy, these mice do not have a bias for REM sleep or any other state.

Although orexin KO mice had fragmented NREM sleep, they had the same distribution of EEG power during NREM sleep, with most energy concentrated in the delta range (Fig. 4). Orexin KO mice also had a normal distribution of EEG power during REM sleep, with normal energy in the theta range. As reported previously (Willie et al., 2003), the spectral distribution of EEG power during cataplexy did not differ from that of REM sleep.

\section{Sleep-wake behavior in constant darkness}

Circadian rhythms generated by the SCN control the timing of wake and REM sleep, perhaps partly via projections to the orexin neurons that then relay this information to sleep-regulatory and wake-regulatory regions (Abrahamson et al., 2001; Aston-Jones et al., 2001; Lu et al., 2001; Chou et al., 2003). To determine whether the abnormal sleep-wake behavior of orexin $\mathrm{KO}$ mice is a consequence of poor circadian control, we studied mice that were free running in constant darkness.

The mean period of the free-running body temperature rhythm was $24.0 \pm 0.1 \mathrm{hr}$ in WT mice and $23.9 \pm 0.1 \mathrm{hr}$ in orexin KO mice. When analyzed as a function of circadian time, both groups showed similar free-running sleep-wake behavior, with no statistical difference in the hourly amounts of wake, NREM, or REM sleep (Fig. 5A). During the $12 \mathrm{hr}$ subjective dark and light periods, the mean amounts of wake, NREM, and REM sleep were the same in WT and orexin KO mice (Fig. 5B), except that orexin KO mice had slightly less wake during the subjective light period. The amplitudes of sleep and wake rhythms were the same in both groups (no significant differences in the circadian indices of wake, NREM, and REM sleep). Compared with the LD condition (Fig. 1), both groups had less wakefulness and more NREM sleep at the beginning of the subjective dark period, thus slightly flattening their rhythms of sleep-wake behavior, as has been reported previously (Trachsel et al., 1986). In contrast to the LD condition, orexin KO mice had a small amount of cataplexy $(20 \%$ of the daily total) during the subjective light period, but the total amount of cataplexy over $24 \mathrm{hr}$ was unchanged.

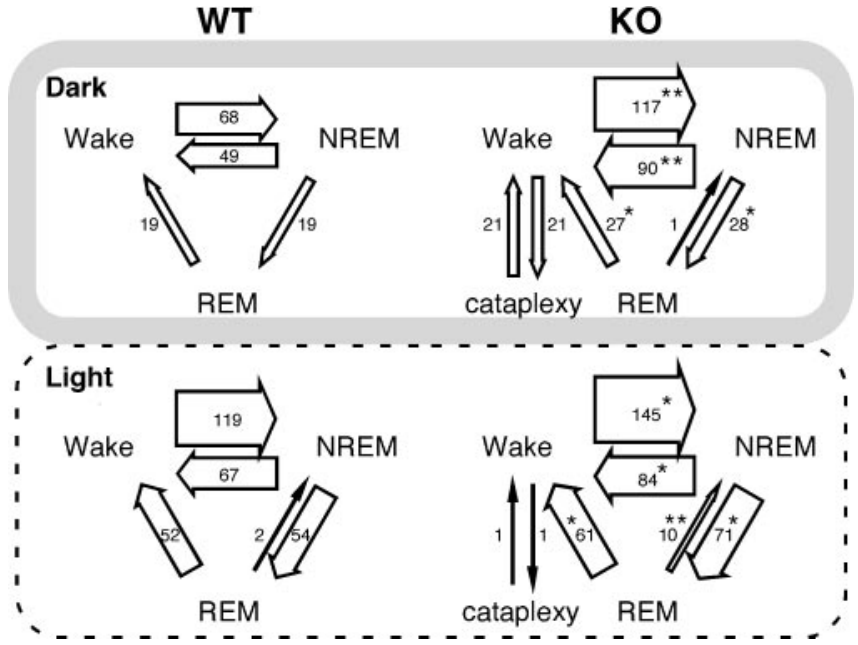

Figure 3. Orexin $\mathrm{KO}$ mice have more transitions between all behavioral states. The mean number of transitions between states is indicated along the arrows between states and by the thickness of the arrows. All transitions are significantly increased in orexin KO mice, and transitions into cataplexy account for only a small number of the transitions out of wakefulness. ${ }^{*} p<$ $0.05 ;{ }^{* *} p<0.01$.

The mean duration of wake and NREM sleep bouts was much shorter at all times in the orexin $\mathrm{KO}$ mice, and REM bouts were shorter during the subjective light period (Fig. 6A). The number of sleep and wake bouts was substantially increased at all times (Fig. 6B). Analysis of wake bout lengths during the subjective dark showed a pattern very similar to that seen in LD (Fig. 6C): $66 \%$ of wake in WT mice occurred in bouts longer than $1280 \mathrm{sec}$, but $86 \%$ of wake in orexin KO mice lasted only $80-1270 \mathrm{sec}$, with no bouts longer than $2560 \mathrm{sec}$. This preservation of the rhythms 

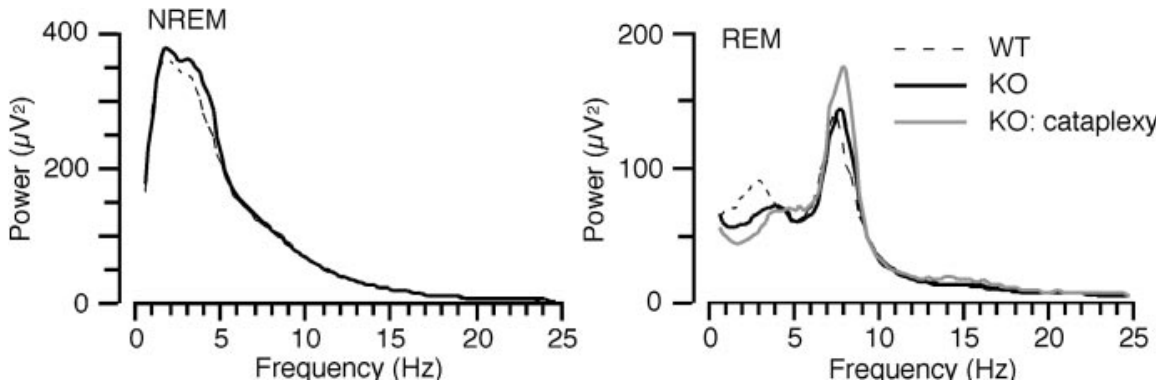

Figure 4. The distribution of EEG power during NREM and REM sleep is similar in WT and orexin KO mice. During cataplexy, the EEG spectra of orexin KO mice is very similar to that seen in REM sleep. The data include all artifact-free sleep and cataplexy epochs during the $12 \mathrm{hr}$ dark period.
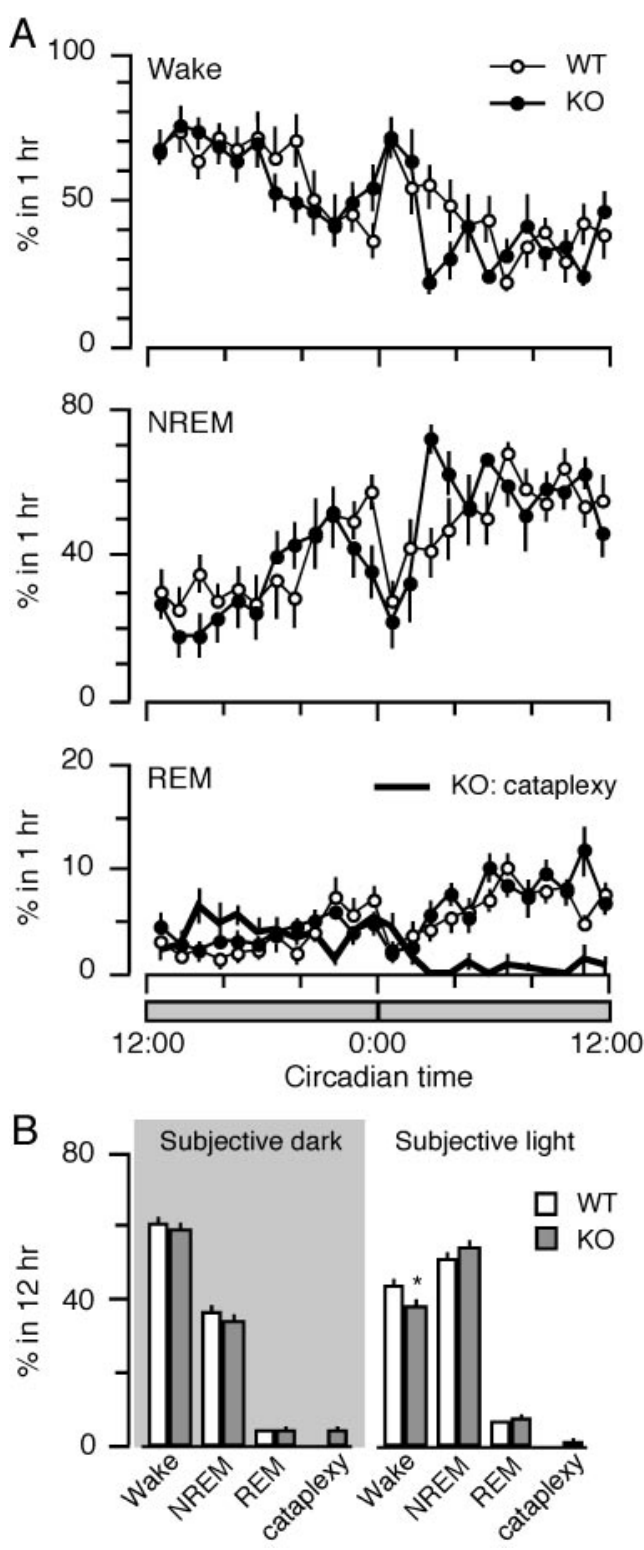

Figure 5. In constant darkness, orexin $\mathrm{KO}$ mice have nearly normal amounts of wakefulness and sleep. $A$, Orexin KO and WT mice have similar hourly amounts of wake, NREM, and REM sleep. As in the LD condition, most cataplexy occurs during the subjective dark period. B, Across the subjective dark and light periods, orexin KO mice have nearly normal amounts of wake, NREM, and REM sleep, except for slightly less wake during the subjective light period. ${ }^{*} p<0.05$. of sleep and wakefulness in constant darkness suggests that impaired circadian timing is not the cause of the brief bouts of wakefulness in orexin $\mathrm{KO}$ mice.

\section{Effects of cage change}

The propensity of orexin $\mathrm{KO}$ mice to have very short bouts of wakefulness could result from a defect in fundamental arousal mechanisms. For example, mice lacking histamine or norepinephrine cannot remain awake as long as WT littermates when placed in a new environment (Parmentier et al., 2002; Hunsley and Palmiter, 2003). To test the integrity of these fundamental arousal regions, we placed mice in a new, clean cage at 1:00 P.M. Both WT and orexin KO mice had sudden increases in wakefulness, accompanied by substantial increases in locomotor activity and body temperature (Fig. $7 A$ ). The mean latency to the onset of NREM sleep was $48.4 \mathrm{~min}$ in the orexin $\mathrm{KO}$ mice and $47.0 \mathrm{~min}$ in the WT mice (Fig. $7 B$ ). These values are in the same range as those observed in WT littermates of histamine- or norepinephrine-deficient mice. Wake bouts of this duration hardly ever occurred in undisturbed $\mathrm{KO}$ mice in the light period and were very rare even during the dark period (Fig. $2 C$ ). This ability of orexin $\mathrm{KO}$ mice to remain awake in a new environment contrasts sharply with the short sleep latencies seen in mice lacking histamine or norepinephrine (Parmentier et al., 2002; Hunsley and Palmiter, 2003).

Orexin $\mathrm{KO}$ mice did have some small differences in their response to cage change. First, the latency to the onset of REM sleep was shorter in orexin $\mathrm{KO}$ mice (52.2 min after cage change vs 68.9 min in WT mice; $p<0.01$ ) (Fig. 7B). Second, WT mice were generally asleep during the 60-80 min period after the cage change, but orexin $\mathrm{KO}$ mice were primarily awake during this time, although their behavior was variable (genotype $\times$ time for the 120 min after cage change, $F=2.78 ; p<0.01$ ). Slightly higher levels of locomotor activity (genotype $\times$ time, $F=3.07 ; p<0.01$ ) and body temperature (genotype $\times$ time, $F=3.60 ; p<0.01$ ) accompanied this waking in $\mathrm{KO}$ mice. Thus, although orexin $\mathrm{KO}$ mice fall asleep as rapidly as WT mice, they wake soon after, perhaps reflecting their poor maintenance of sleep.

\section{Sleep deprivation and recovery sleep}

Some researchers have hypothesized that short sleep latencies in narcolepsy result from abnormal sleep homeostasis, with an inappropriately rapid accumulation or intense expression of sleep pressure (Tafti et al., 1992a,b; Besset et al., 1994). To examine sleep homeostasis, we gently handled mice to deprive them of sleep for 2, 4, or $8 \mathrm{hr}$, beginning at lights on. Gentle handling prevented the mice from sleeping almost completely for $2 \mathrm{hr}$, but, during the longer sleep deprivations, brief episodes of NREM sleep occurred in both groups. Specifically, during the $8 \mathrm{hr}$ of sleep deprivation, WT and orexin KO mice spent a total of 13 and 15 min in NREM sleep, respectively ( $p=N S$ ). More stimuli were required to maintain wake in the orexin $\mathrm{KO}$ mice because they had an average of 45 transitions into NREM sleep, whereas WT mice entered NREM sleep an average of 28 times $(p<0.05)$. However, the time course of these attempts to sleep was similar in the two groups, with most wake to NREM sleep transitions occurring after $6 \mathrm{hr}$ of sleep deprivation.

In the hours after the sleep deprivation, all animals had more NREM sleep than on their baseline day. For example, after $8 \mathrm{hr}$ of 

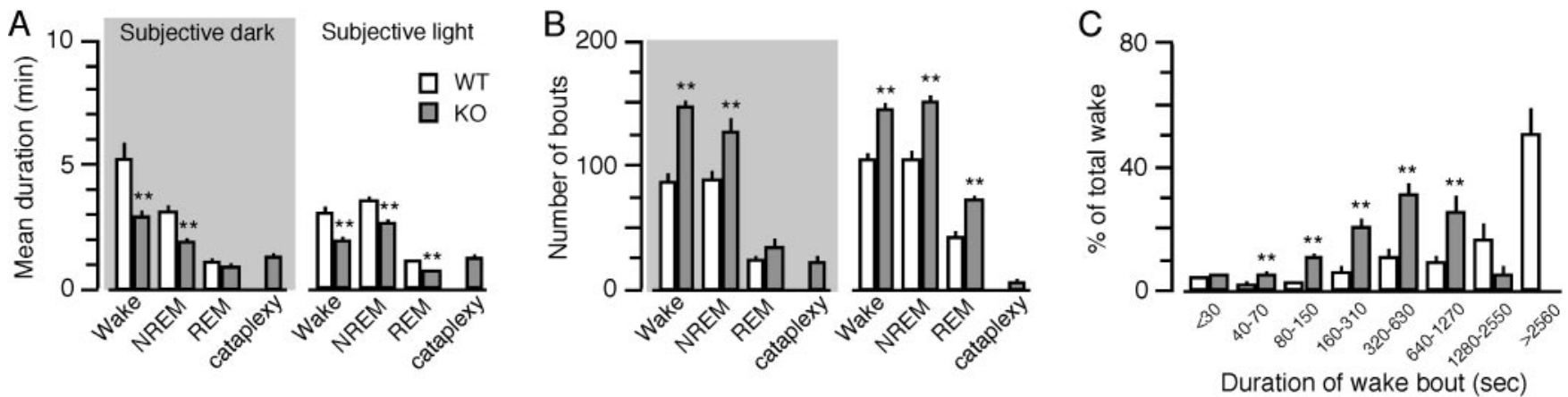

Figure 6. Orexin KO mice have fragmented sleep and wake in constant darkness. $A, B$, Orexin $\mathrm{K} 0$ mice have shorter and more frequent bouts of wake and NREM sleep, but these abnormalities are apparent in REM sleep only during the subjective light period. A few episodes of cataplexy occur in the subjective light period. C, During the subjective dark period, most wakefulness in orexin $\mathrm{KO}$ mice occurs in short- to mid-length bouts. ${ }^{* *} p<0.01$.
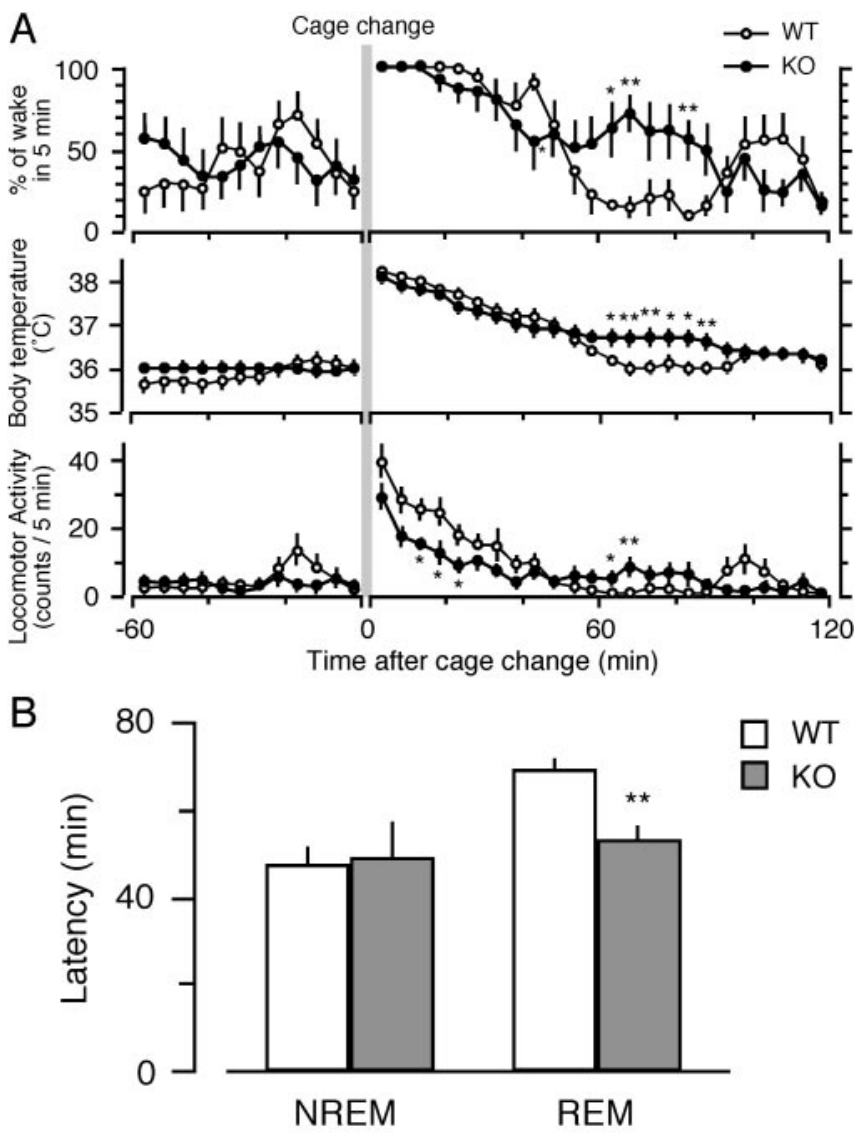

Figure 7. Placing WT and orexin K0 in new, clean cages at 1:00 P.M. increases wakefulness, body temperature, and locomotor activity. $A$, After an initial period of wakefulness, both groups return to sleep after $45 \mathrm{~min}$, but, $60-90$ min after cage change, orexin $\mathrm{K} 0$ mice have more wakefulness and a small rise in body temperature. Orexin $\mathrm{KO}$ mice also have a smaller initial increase in locomotor activity. $B$, After cage change, orexin $\mathrm{KO}$ mice remain awake for over 45 min just as seen in WT mice, but they enter REM sleep more rapidly. ${ }^{*} p<0.05 ;{ }^{* *} p<0.01$.

sleep deprivation, both WT and orexin KO mice had 25\% more NREM sleep in the subsequent $4 \mathrm{hr}$, and this rebound sleep persisted into the dark period (Fig. 8). The time course of recovery NREM sleep did not differ between WT and KO mice (genotype $\times$ time, $F=1.53 ; p=0.10$ ). REM sleep was recovered more slowly, perhaps because of the initial preponderance of NREM sleep, and orexin KO mice had slightly more REM sleep than WT mice did during a few hours of the dark period (genotype $\times$ time, $F=2.77 ; p<0.001)$.
To examine the kinetics of recovery sleep, we calculated the cumulative change in the amounts of NREM and REM sleep compared with the baseline day. With $8 \mathrm{hr}$ of sleep deprivation, both groups of mice accumulated NREM and REM sleep deficits of $\sim 240$ and 40 min, respectively (Fig. 9A). During the subsequent 16 hr recovery period, these deficits were partially recovered because the animals had higher than normal amounts of sleep. Both groups recovered NREM sleep at the same rate (WT, 6.9; KO, $8.5 \mathrm{~min} / \mathrm{hr}$ recovery NREM sleep; $p=$ NS) and to the same extent (deficits at the end of the recordings, -126.5 and $-128.7 \mathrm{~min}$ in $\mathrm{WT}$ and $\mathrm{KO}$ mice; $p=$ NS). WT and orexin KO mice also recovered their REM sleep deficits at the same rate $(\mathrm{WT}, 1.7 ; \mathrm{KO}, 1.5 \mathrm{~min} / \mathrm{hr}$ recovery $\mathrm{REM}$ sleep; $p=\mathrm{NS})$ and to the same extent $(-15.1$ and $-19.5 \mathrm{~min}$ in WT and $\mathrm{KO}$ mice; $p=\mathrm{NS}$ ).

The duration of NREM sleep bouts often increases after sleep deprivation, and so we determined the length of NREM sleep bouts during the first $4 \mathrm{hr}$ of recovery (Fig. 9B). After $8 \mathrm{hr}$ of sleep deprivation, both groups had NREM sleep bouts that were $\sim 60 \%$ longer than during the corresponding period on the baseline day (3:00-7:00 P.M.; WT means: $166 \pm 7$ and $288 \pm 20 \mathrm{sec}$ on the baseline and recovery days, condition $\times$ bouts, $F=14.48$, $p<0.001$; KO means: $121 \pm 5$ and $194 \pm 21 \mathrm{sec}, F=10.65, p<$ $0.001)$. Although NREM sleep was more consolidated during recovery, KO mice still had fragmented NREM sleep (genotype $\times$ bouts, $F=3.90$; $p<0.001)$, with more short bouts of NREM sleep $(40-150 \mathrm{sec} ; p<0.01)$ and fewer long bouts of NREM sleep $(320-630$ sec; $p<0.01)$ than WT mice. Thus, even after a period of prolonged wakefulness, orexin $\mathrm{KO}$ mice continued to have NREM sleep fragmentation.

Orexin KO mice had normal responses to sleep deprivation using several other measures of sleep homeostasis. With 2, 4, or 8 hr of sleep deprivation, WT and orexin KO mice produced similar amounts of rebound NREM and REM sleep in a dosedependent manner (Fig. 10A). Sleep deprivation also shortened the latencies to enter NREM or REM sleep in both groups, with shorter latencies in the more sleep-deprived animals (Fig. 10B). Although KO mice tended to fall asleep sooner than WT mice after the sleep deprivation, this effect was statistically significant only in the very short latency to enter REM sleep after $8 \mathrm{hr}$ of sleep deprivation. EEG delta power during NREM sleep may reflect homeostatic sleep need (Borbély and Tobler, 1996), and sleep deprivation dose dependently increased NREM sleep delta power during the first $4 \mathrm{hr}$ of recovery, with no significant difference between WT and orexin KO mice (Fig. 10C). In both groups of mice, this increased delta power declined gradually over the first several hours of the recovery period (supplemental Fig. 2, 

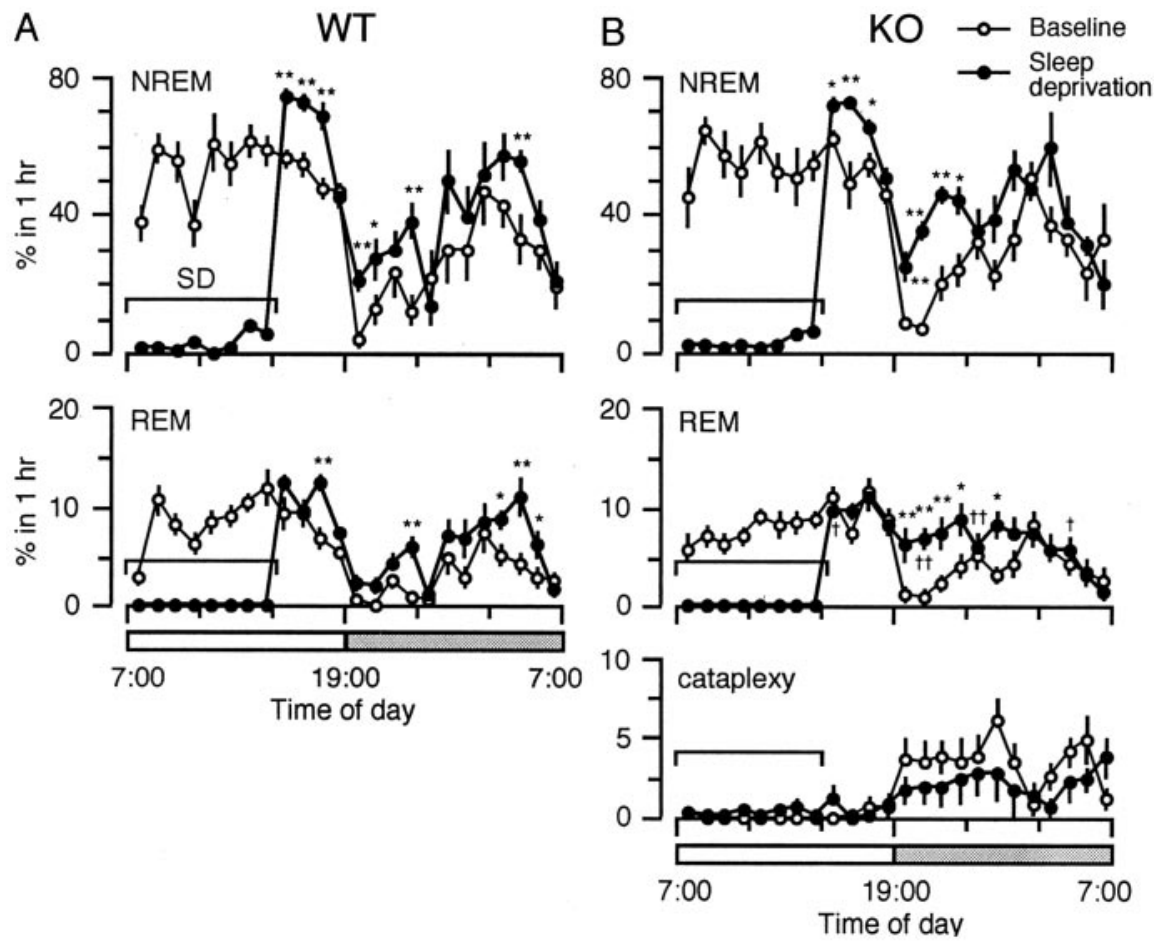

Figure 8. Orexin $\mathrm{KO}$ mice have nearly normal responses to $8 \mathrm{hr}$ of sleep deprivation. A, Compared with the baseline day (open circles), WT mice have a marked increase in NREM sleep after $8 \mathrm{hr}$ of sleep deprivation (filled circles). WT mice also have rebound REM sleep, primarily during the dark period. $B$, Orexin knock-out mice have normal rebound of NREM sleep but relatively more rebound REM sleep during the dark period. Although not statistically significant, cataplexy appears to be less frequent after sleep deprivation. Horizontal brackets mark the sleep deprivation (SD) period. ${ }^{*} p<0.05 ;{ }^{* *} p<0.01$ compared with the baseline day. $\dagger p<0.05 ; \dagger+p<0.01$ compared with WT mice on the sleep deprivation day.

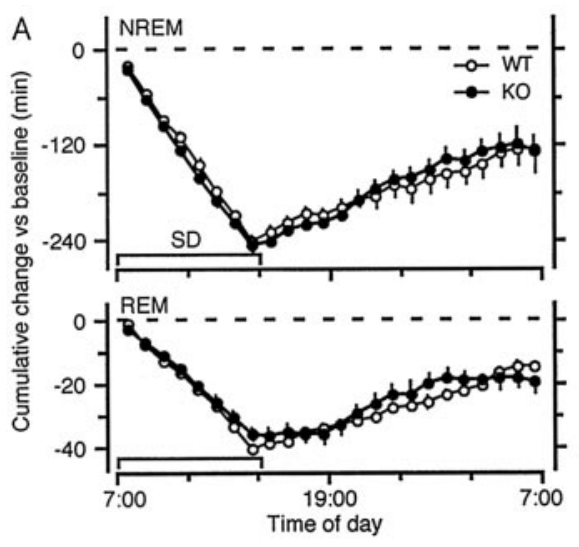

Figure 9. After sleep deprivation, orexin KO mice recover NREM and REM sleep normally, but NREM sleep is still fragmented. $A$, When compared with the baseline day, both WT and orexin KO mice accumulate a NREM sleep deficit of $\sim 240 \mathrm{~min}$ over the $8 \mathrm{hr}$ of sleep deprivation. Both groups then recover from this deficit at the same rate and to the same extent. $B$, At baseline, orexin $K O$ mice have shorter bouts of NREM sleep than WT mice. After $8 \mathrm{hr}$ of sleep deprivation, both groups produce longer bouts of NREM sleep, but orexin KO mice still have shorter than normal NREM bouts. ${ }^{*} p<0.05$; ${ }^{* *} p<0.01$.

available at www.jneurosci.org/cgi/content/full/24/28/6291/ DC1). As a control, EEG theta power in REM sleep was also measured and showed no changes. Thus, across a variety of measures, orexin $\mathrm{KO}$ mice appear to have normal homeostatic responses to sleep deprivation.

\section{Discussion}

Excessive daytime sleepiness or an inability to sustain wakefulness is the most disabling symptom for patients with narcolepsy, and orexin $\mathrm{KO}$ mice have very short bouts of wakefulness. These experiments demonstrate that this inability to maintain wakefulness is probably not caused by poor circadian promotion of wakefulness, defective fundamental arousal systems, or abnormal homeostatic regulation of sleep. Because orexin-deficient mice have more transitions between all states, their phenotype may best be described as behavioral state instability, with apparently low thresholds to transition between all behavioral states.

\section{Technical considerations}

Across all conditions, we found that orexin KO mice have essentially normal amounts of wake, NREM, and REM sleep, just as seen in people and dogs with narcolepsy (Dantz et al., 1994; Broughton et al., 1998; Nishino et al., 2000). Previous studies of orexin $\mathrm{KO}$ mice reported increased REM sleep during the dark period (Chemelli et al., 1999; Willie et al., 2003), but REM sleep may have simply appeared increased because these studies did not separate cataplexy from REM sleep. We operationally defined cataplexy as atonia with EEG theta activity that is immediately preceded and followed by active wake. Without video recordings in all experiments, we may have overlooked some cataplexy, but $80 \%$ of all cataplexy episodes can be detected using these EEG and EMG criteria (Willie et al., 2003).

Circadian control of sleep-wake behavior is normal in orexin $\mathrm{KO}$ mice The daytime sleepiness and fragmented sleep of narcolepsy could be caused by impaired circadian control (Kripke, 1976; Dantz et al., 1994; Broughton et al., 1998). Circadian signals help time and consolidate sleep-wake behavior, and the orexin neurons are well positioned to relay circadian information to state-regulatory regions (Abrahamson et al., 2001; AstonJones et al., 2001; Lu et al., 2001; Chou et al., 2003). In the absence of orexin, the amplitude of the circadian signals that time sleep-wake behavior might be reduced, resulting in brief episodes of wake, fragmented sleep, and inappropriately timed REM sleep.

Willie and colleagues showed that orexin $\mathrm{KO}$ mice have relatively normal timing of sleep and wake when housed in an LD cycle (Willie et al., 2003), but the light cycle might mask any underlying circadian defects. We studied orexin $\mathrm{KO}$ mice in constant darkness and found that their body temperature rhythm has a normal free-running period, indicating normal timing in the SCN. More importantly, the amplitude and timing of their sleep-wake rhythms was normal, demonstrating that orexin is unnecessary for the timing of sleep and 
A

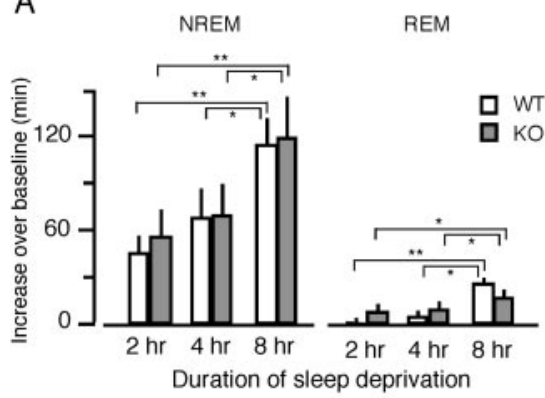

B

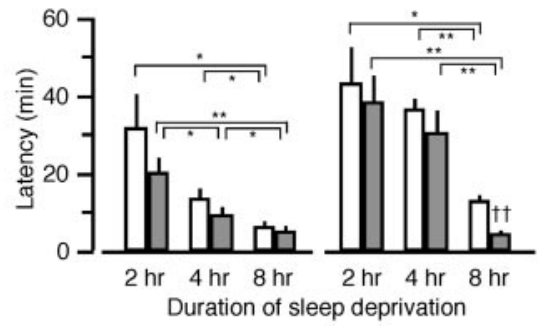

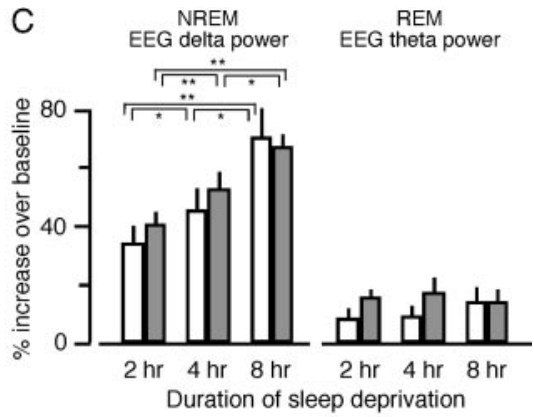

Figure 10. Orexin $\mathrm{KO}$ mice have normal, dose-dependent responses to sleep deprivation. $A$, The amount of rebound NREM and REM sleep in the $4 \mathrm{hr}$ immediately after sleep deprivation increases in proportion to the duration of sleep deprivation. $B$, In both groups, the latency to enter NREM and REM sleep becomes shorter with increasing durations of sleep deprivation. Latencies are similar between groups, except that orexin $\mathrm{KO}$ mice enter REM sleep more rapidly after $8 \mathrm{hr}$ of sleep deprivation. C, EEG delta power (0.5- $4 \mathrm{~Hz})$ during NREM sleep in the $4 \mathrm{hr}$ after sleep deprivation increases with increasing duration of sleep deprivation in both groups. Theta power $(4-9 \mathrm{~Hz})$ during REM sleep does not change with sleep deprivation. ${ }^{*} p<0.05$; ${ }^{* *} p<0.01$ compared with other durations of sleep deprivation. $+1 p<0.01$ compared with WT mice.

wake. These results suggest that the fragmented sleep-wake behavior of orexin $\mathrm{KO}$ mice is not a consequence of poor circadian control.

\section{Fundamental arousal mechanisms are intact in orexin KO mice}

Wakefulness is promoted by ascending projections from aminergic and cholinergic nuclei, including noradrenergic neurons of the LC and histaminergic neurons of the TMN. Mice lacking norepinephrine or histamine fall asleep rapidly after a mild stress, such as transfer to a new cage (Parmentier et al., 2002; Hunsley and Palmiter, 2003), demonstrating that these arousal regions are necessary for responding to challenges. Because the orexin neurons send heavy, excitatory projections to the LC, TMN, and many other arousal regions (Peyron et al., 1998), the short bouts of wake in orexin $\mathrm{KO}$ mice might be a consequence of inadequate activation of these fundamental arousal regions.

To test this hypothesis, we transferred mice to a new cage in the middle of their sleep period. We found that orexin $\mathrm{KO}$ mice remained awake just as long as WT mice, and their sleep latency was quite similar to WT mice in other studies (Parmentier et al., 2002; Hunsley and Palmiter, 2003). Therefore, even in the absence of orexin, fundamental arousal regions, including the LC and TMN, can be sufficiently engaged by a mild stress for the sustained production of wakefulness. Nevertheless, we cannot conclude that aminergic activity is entirely normal in orexin $\mathrm{KO}$ mice under baseline, unstimulated conditions. Extracellular recordings from freely moving orexin $\mathrm{KO}$ mice are needed to determine whether the level and pattern of activity in aminergic neurons is normal.

\section{NREM sleep homeostasis is normal in orexin $\mathrm{KO}$ mice}

Increased sleep pressure from abnormal sleep homeostasis is also hypothesized to cause the excessive daytime sleepiness of narcolepsy. For example, the greatest propensity for napping occurs 2.5 hr earlier in narcoleptics than in control individuals who habitually take a nap (Broughton et al., 1998). In addition, after $24 \mathrm{hr}$ of sleep deprivation, people with narcolepsy have shorter sleep latencies and more stage 3 and 4 NREM sleep compared with controls, suggesting a more rapid accumulation of or heightened sensitivity to sleep pressure in narcolepsy (Tafti et al., 1992b).

To examine this sleep homeostasis hypothesis, we deprived orexin $\mathrm{KO}$ mice of sleep and then examined their subsequent recovery. As expected, sleep deprivation dose dependently shortened the latencies to enter NREM or REM sleep, increased the amounts of NREM and REM sleep, and increased NREM sleep EEG delta power in both WT and KO mice. Across these experiments, the responses of orexin $\mathrm{KO}$ mice were entirely normal, except they rapidly entered and had slightly more REM sleep than WT mice after $8 \mathrm{hr}$ of sleep deprivation. In addition, orexin $\mathrm{KO}$ mice recovered their NREM and REM sleep deficits at the same rate and to the same extent as WT mice. Thus, consistent with some previous clinical studies (Volk et al., 1990; Dantz et al., 1994), the accumulation and expression of homeostatic "sleep drive" is normal in orexin $\mathrm{KO}$ mice.

\section{Behavioral state instability}

Our studies primarily focused on the poor maintenance of wakefulness in orexin $\mathrm{KO}$ mice, but these mice also have fragmented NREM sleep, even after $8 \mathrm{hr}$ of sleep deprivation. In fact, orexin KO mice have considerably more transitions between all states, as has been noted in people and dogs with narcolepsy (de BarrosFerreira and Lairy, 1976; Kaitin et al., 1986; Nishino et al., 2000; Mukai et al., 2003). Sleep cycles in orexin KO mice still generally progress from wake to NREM and then to REM sleep, and, with the exception of cataplexy, there is no bias toward any particular state. Thus, the increased number of transitions is not a consequence of pressure for NREM or REM sleep but may represent a process of behavioral state instability in which a breakdown of neural control processes reduces the thresholds to transition between all states.

Reduced activity in arousal regions could explain the frequent transitions from wake into NREM sleep. The orexin neurons may be persistently active during wakefulness (Alam et al., 2002; Li et al., 2002; Eggermann et al., 2003), helping to sustain activity in aminergic and cholinergic arousal regions. In the absence of orexin, these arousal regions may have reduced or vacillating activity, resulting in inappropriately low thresholds to transition into NREM sleep. For example, during the $8 \mathrm{hr}$ of sleep deprivation, orexin KO mice had 60\% more transitions into NREM sleep than WT mice, although their sleep homeostasis appears normal.

The frequent awakenings from NREM sleep in orexin KO mice are probably not caused by low sleep drive, although they typically enter sleep after short periods of wake. EEG delta power during NREM sleep rises in relation to sleep propensity (Borbély and Tobler, 1996), and orexin KO mice have normal NREM delta power. In addition, after accumulating substantial sleep pressure with $8 \mathrm{hr}$ of sleep deprivation, their sleep was still fragmented, just as seen in people with narcolepsy (Tafti et al., 1992a,b). Awakenings from NREM sleep also might occur if orexin KO mice rapidly 
dissipate sleep pressure, but this appears unlikely because they recovered their NREM deficit at a normal rate after $8 \mathrm{hr}$ of sleep deprivation.

More likely, NREM sleep is disrupted by uncoordinated activity in sleep-wake systems. The orexin neurons are probably inactive during NREM sleep (Estabrooke et al., 2001; Alam et al., 2002), but excitation of arousal regions by orexin during wake might induce lasting changes in neuronal activity that help persistently silence these regions during sleep. Lack of orexin signaling might cause noisy or disorganized activity in downstream aminergic nuclei, which would sporadically inhibit the sleepproducing neurons of the ventrolateral preoptic area (Sherin et al., 1996; Gallopin et al., 2000; Saper et al., 2001). This noise could result in a faster sleep cycle or simply more random state changes. Perhaps, such disorganized activity underlies the ambiguous or "intermediate" sleep of narcolepsy in which atonia or saccadic eye movements occur during NREM sleep and bursts of muscle activity occur during REM sleep (de Barros-Ferreira and Lairy, 1976; Schenck and Mahowald, 1992). Electrophysiologic studies of state control neurons in narcoleptic animals will be needed to determine whether the activity of sleep-wake regulatory regions is truly disorganized.

Long before the discovery of orexin, Broughton hypothesized that the fundamental problem in narcolepsy was a loss of the "neurochemical glues" that help integrate neuronal activity to produce stable sleep-wake behavior (Broughton et al., 1986). Most likely, he was correct because a loss of orexin appears to lower the thresholds to transition between behavioral states, producing the fragmented wakefulness and sleep of narcolepsy.

\section{References}

Abrahamson EE, Leak RK, Moore RY (2001) The suprachiasmatic nucleus projects to posterior hypothalamic arousal systems. NeuroReport 12:435-440.

Alam MN, Gong H, Alam T, Jaganath R, McGinty D, Szymusiak R (2002) Sleep-waking discharge patterns of neurons recorded in the rat perifornical lateral hypothalamic area. J Physiol (Lond) 538:619-631.

Aston-Jones G, Chen S, Zhu Y, Oshinsky ML (2001) A neural circuit for circadian regulation of arousal. Nat Neurosci 4:732-738.

Besset A, Tafti M, Nobile L, Billiard M (1994) Homeostasis and narcolepsy. Sleep 17:S29-S34.

Borbély AA, Tobler I (1996) Sleep regulation: relation to photoperiod, sleep duration, waking activity, and torpor. In: Progress in brain research (Buijs RM, Kalsbeek A, Romijn HJ, Pennartz CMA, Nirmiran M, eds), pp 343348. Amsterdam: Elsevier.

Bourgin P, Huitron-Resendiz S, Spier AD, Fabre V, Morte B, Criado JR, Sutcliffe JG, Henriksen SJ, de Lecea L (2000) Hypocretin-1 modulates rapid eye movement sleep through activation of locus coeruleus neurons. J Neurosci 20:7760-7765.

Broughton R, Mullington J (1994) Chronobiological aspects of narcolepsy. Sleep 17 [Suppl 8]:S35-S44.

Broughton R, Valley V, Aguirre M, Roberts J, Suwalski W, Dunham W (1986) Excessive daytime sleepiness and the pathophysiology of narcolepsy-cataplexy: a laboratory perspective. Sleep 9:205-215.

Broughton R, Krupa S, Boucher B, Rivers M, Mullington J (1998) Impaired circadian waking arousal in narcolepsy-cataplexy. Sleep Res Online 1:159-165.

Chemelli RM, Willie JT, Sinton CM, Elmquist JK, Scammell T, Lee C, Richardson JA, Williams SC, Xiong Y, Kisanuki Y, Fitch TE, Nakazato M, Hammer RE, Saper CB, Yanagisawa M (1999) Narcolepsy in orexin knockout mice: molecular genetics of sleep regulation. Cell 98:437-451.

Chou TC, Scammell TE, Gooley JJ, Gaus SE, Saper CB, Lu J (2003) Critical role of dorsomedial hypothalamic nucleus in a wide range of behavioral circadian rhythms. J Neurosci 23:10691-10702.

Dantz B, Edgar DM, Dement WC (1994) Circadian rhythms in narcolepsy: studies on a 90 minute day. Electroencephalogr Clin Neurophysiol 90:24-35

de Barros-Ferreira M, Lairy GC (1976) Ambiguous sleep in narcolepsy. In:
Narcolepsy (Guilleminault C, Dement WC, Passouant P, eds), pp 57-75. New York: Spectrum.

Dijk DJ, Czeisler CA (1995) Contribution of the circadian pacemaker and the sleep homeostat to sleep propensity, sleep structure, electroencephalographic slow waves, and sleep spindle activity in humans. J Neurosci 15:3526-3538.

Dyken ME, Yamada T, Lin-Dyken DC, Seaba P (1994) Narcolepsy: unequivocal diagnosis after split-screen, video-polysomnographic analysis of a prolonged cataplectic attack. Neurology 44:760-761.

Edgar DM, Dement WC, Fuller CA (1993) Effect of SCN lesions on sleep in squirrel monkeys: evidence for opponent processes in sleep-wake regulation. J Neurosci 13:1065-1079.

Eggermann E, Serafin M, Bayer L, Machard D, Saint-Mleux B, Jones BE, Mühlethaler M (2001) Orexins/hypocretins excite basal forebrain cholinergic neurones. Neuroscience 108:177-181.

Eggermann E, Bayer L, Serafin M, Saint-Mleux B, Bernheim L, Machard D, Jones BE, Mühlethaler M (2003) The wake-promoting hypocretinorexin neurons are in an intrinsic state of membrane depolarization. J Neurosci 23:1557-1562.

Eriksson KS, Sergeeva O, Brown RE, Haas HL (2001) Orexin/hypocretin excites the histaminergic neurons of the tuberomammillary nucleus. J Neurosci 21:9273-9279.

Estabrooke IV, McCarthy MT, Ko E, Chou TC, Chemelli RM, Yanagisawa M, Saper CB, Scammell TE (2001) Fos expression in orexin neurons varies with behavioral state. J Neurosci 21:1656-1662.

Franken P, Malafosse A, Tafti M (1999) Genetic determinants of sleep regulation in inbred mice. Sleep 22:155-169.

Gallopin T, Fort P, Eggermann E, Cauli B, Luppi PH, Rossier J, Audinat E, Mühlethaler M, Serafin M (2000) Identification of sleep-promoting neurons in vitro. Nature 404:992-995.

Guilleminault C, Wilson RA, Dement WC (1974) A study on cataplexy. Arch Neurol 31:255-261.

Hagan JJ, Leslie RA, Patel S, Evans ML, Wattam TA, Holmes S, Benham CD, Taylor SG, Routledge C, Hemmati P, Munton RP, Ashmeade TE, Shah AS, Hatcher JP, Hatcher PD, Jones DN, Smith MI, Piper DC, Hunter AJ, Porter RA, Upton N (1999) Orexin A activates locus coeruleus cell firing and increases arousal in the rat. Proc Natl Acad Sci USA 96:10911-10916.

Huang ZL, Qu WM, Li WD, Mochizuki T, Eguchi N, Watanabe T, Urade Y, Hayaishi O (2001) Arousal effect of orexin A depends on activation of the histaminergic system. Proc Natl Acad Sci USA 98:9965-9970.

Hunsley MS, Palmiter RD (2003) Norepinephrine-deficient mice exhibit normal sleep-wake states but have shorter sleep latency after mild stress and low doses of amphetamine. Sleep 26:521-526.

John J, Wu MF, Boehmer LN, Siegel JM (2004) Cataplexy-active neurons in the hypothalamus: implications for the role of histamine in sleep and waking behavior. Neuron 42:619-634.

Kaitin KI, Kilduff TS, Dement WC (1986) Sleep fragmentation in canine narcolepsy. Sleep 9:116-119.

Klein DC, Moore RY, Reppert SM (1991) Suprachiasmatic nucleus: the mind's clock. New York: Oxford UP.

Kripke DF (1976) Biological rhythm disturbances might cause narcolepsy. In: Narcolepsy (Guilleminault C, Dement WC, Passouant P, eds), pp 475-483. New York: Spectrum.

Li Y, Gao XB, Sakurai T, van den Pol AN (2002) Hypocretin/orexin excites hypocretin neurons via a local glutamate neurons-a potential mechanism for orchestrating the hypothalamic arousal system. Neuron 36:1169-1181.

Lu J, Zhang YH, Chou TC, Gaus SE, Elmquist JK, Shiromani P, Saper CB (2001) Contrasting effects of ibotenate lesions of the paraventricular nucleus and subparaventricular zone on sleep-wake cycle and temperature regulation. J Neurosci 21:4864-4874.

Mignot E, Lammers GJ, Ripley B, Okun M, Nevsimalova S, Overeem S, Vankova J, Black J, Harsh J, Bassetti C, Schrader H, Nishino S (2002) The role of cerebrospinal fluid hypocretin measurement in the diagnosis of narcolepsy and other hypersomnias. Arch Neurol 59:1553-1562.

Mistlberger RE, Bergmann BM, Waldenar W, Rechtschaffen A (1983) Recovery sleep following sleep deprivation in intact and suprachiasmatic nuclei-lesioned rats. Sleep 6:217-233.

Mitler MM, Dement WC (1977) Sleep studies on canine narcolepsy: pattern and cycle comparisons between affected and normal dogs. Electroencephalogr Clin Neurophysiol 43:691-699.

Mukai J, Uchida S, Miyazaki S, Nishihara K, Honda Y (2003) Spectral anal- 
ysis of all-night human sleep EEG in narcoleptic patients and normal subjects. J Sleep Res 12:63-71.

Nishino S, Riehl J, Hong J, Kwan M, Reid M, Mignot E (2000) Is narcolepsy a REM sleep disorder? Analysis of sleep abnormalities in narcoleptic Dobermans. Neurosci Res 38:437-446.

Nobili L, Besset A, Ferrillo F, Rosadini G, Schiavi G, Billiard M (1995) Dynamics of slow wave activity in narcoleptic patients under bed rest conditions. Electroencephalogr Clin Neurophysiol 95:414-425.

Parmentier R, Ohtsu H, Djebbara-Hannas Z, Valatx JL, Watanabe T, Lin JS (2002) Anatomical, physiological, and pharmacological characteristics of histidine decarboxylase knock-out mice: evidence for the role of brain histamine in behavioral and sleep-wake control. J Neurosci 22:7695-7711.

Peyron C, Tighe DK, van den Pol AN, de Lecea L, Heller HC, Sutcliffe JG, Kilduff TS (1998) Neurons containing hypocretin (orexin) project to multiple neuronal systems. J Neurosci 18:9996-10015.

Saper CB, Chou TC, Scammell TE (2001) The sleep switch: hypothalamic control of sleep and wakefulness. Trends Neurosci 24:726-731.

Scammell TE (2003) The neurobiology, diagnosis, and treatment of narcolepsy. Ann Neurol 53:154-166.

Schenck CH, Mahowald MW (1992) Motor dyscontrol in narcolepsy: rapid-eye-movement (REM) sleep without atonia and REM sleep behavior disorder. Ann Neurol 32:3-10.

Sherin JE, Shiromani PJ, McCarley RW, Saper CB (1996) Activation of ventrolateral preoptic neurons during sleep. Science 271:216-219.

Tafti M, Villemin E, Carlander B, Besset A, Billiard M (1992a) Sleep in hu- man narcolepsy revisited with special reference to prior wakefulness duration. Sleep 15:344-351.

Tafti M, Rondouin G, Besset A, Billiard M (1992b) Sleep deprivation in narcoleptic subjects: effect on sleep stages and EEG power density. Electroencephalogr Clin Neurophysiol 83:339-349.

Trachsel L, Tobler I, Borbély AA (1986) Sleep regulation in rats: effects of sleep deprivation, light, and circadian phase. Am J Physiol 251:R1037-R1044.

Trachsel L, Tobler I, Achermann P, Borbély AA (1991) Sleep continuity and the REM-nonREM cycle in the rat under baseline conditions and after sleep deprivation. Physiol Behav 49:575-580.

Volk S, Schulz H, Yassouridis A, Wilde-Frenz J, Simon O (1990) The influence of two behavioral regimens on the distribution of sleep and wakefulness in narcoleptic patients. Sleep 13:136-142.

Willie JT, Chemelli RM, Sinton CM, Tokita S, Williams SC, Kisanuki YY, Marcus JN, Lee C, Elmquist JK, Kohlmeier KA, Leonard CS, Richardson JA, Hammer RE, Yanagisawa M (2003) Distinct narcolepsy syndromes in Orexin receptor-2 and Orexin null mice: molecular genetic dissection of Non-REM and REM sleep regulatory processes. Neuron 38:715-730.

Wu MF, John J, Boehmer LN, Yau D, Nguyen GB, Siegel JM (2004) Activity of dorsal raphe cells across the sleep-waking cycle and during cataplexy in narcoleptic dogs. J Physiol (Lond) 554:202-215.

Yamanaka A, Tsujino N, Funahashi H, Honda K, Guan JL, Wang QP, Tominaga M, Goto K, Shioda S, Sakurai T (2002) Orexins activate histaminergic neurons via the orexin 2 receptor. Biochem Biophys Res Commun 290:1237-1245. 